\title{
Immune deficiency derive a favorable response to IVIg in PANDAS
}

\section{Theresa E. Gildner ${ }^{*}$}

*Corresponding Author : Eric Arthur Blair , Department of Psychology, Oregon, USA. Email: erictheresa456@yahoo.com

Received date: May 10,2018 ;Accepted date : June 21,2018; Published date: July 06,2018.

Citation: Theresa E. Gildner, Immune deficiency derive a favorable response to IVIg in PANDAS. J Psychology and Mental Health Care . Doi: $10.31579 / 2637-8892 / 032$

Copyright : (c) 2018 Theresa E. Gildner. This is an open-access article distributed under the terms of The Creative Commons Attribution License, which permits unrestricted use, distribution, and reproduction in any medium, provided the original author and source are credited.

\section{Abstract \\ Introduction}

For two decades, pediatric autoimmune neuropsychiatric disorder associated with group a beta hemolytic streptococcal infection (PANDAS) has been treated with high-dose intravenous immune globulin (IVIg) therapy based upon the understanding that the disorder is partly due to postinfectious dysimmunity.

\section{Study Aims}

To summarize literature cases of PANDAS treated with IVIg therapy.

\section{Methods}

A search for publications documenting the experience of PANDAS treated with IVIg therapy was carried out in the English-speaking medical literature. This yielded seven articles comprising an observational study (114 patients), a randomized control trial (9 patients), five small case series (21 patients), and a single case abstract, together documenting the experience of 145 published children who met established criteria for the diagnosis of PANDAS and were treated with IVIg therapy for neuropsychiatric symptoms. An analysis of their findings was performed contrasting and combining clinical characteristics and outcomes of cases in each study, and generalizing information with mean values for continuous variables and percentages for character values.

\section{Results}

Sixty percent of children showed overall clinical improvement, $24 \%$ achieved remission of neuropsychiatric symptoms at final assessment, $9 \%$ were unchanged, and none were worse following IVIg therapy at doses between 1.0 and 2.0 grams per kilogram administered every 1 to 2 months for a mean duration of 15.3 months (range 0.03 - 61.79 months) for refractory neuropsychiatric symptoms associated with PANDAS. Only 19 (13\%) of children received a single one month course of therapy. Among 114 patients (15), 49 (35\%) had low baseline Ig levels. Of 22 patients (19.3\%) who achieved remission, all 22 (100\%) had low baseline IgG (20 patients) or IgG subclass levels (2 patients), alone (8 patients) or together (6 patients) or in association with reduced $\operatorname{IgA}$ or IgM levels (8 patients), indicative of humoral deficiency prior to IVIg treatment. One other reported patient who achieved remission status (10) had combined IgG2/4 subclass deficiency.

\section{Conclusions}

Children with PANDAS, often with baseline humoral immune deficiency derive a favorable response to IVIg in PANDAS at 12 months follow up consistent with its role in Ig replacement and immune modulation. While its use has not been substantiated in a large RCT, our findings support its administration early in the course of the disease and continued until significant improvement or remission is achieved often without serious side-effects.

\section{Keywords}

PANDAS; IVIg Therapy

\section{Introduction}

From 1989 to 1992, Swedo and investigators [1-3] in the Child Psychiatry Branch of the National Institute of Mental Health (NIMH) in Bethesda, Maryland described the long-term course of children with obsessive-compulsive disorders (OCD). In 1994, Swedo [4] described a subgroup of children with sudden onset of OCD and tic disorders following group A beta-hemolytic streptococcal (GABHS) infections. An autoimmune process analogous to Sydenham's chorea could be postulated wherein exposure of a child and susceptible host to GABHS infection evoked an autoimmune response in the central nervous system (CNS). Postulating the benefit of immunotherapy in so called pediatric infection-triggered autoimmune neuropsychiatric disorders (PANDAS), Swedo and colleagues [5] established working criteria for the diagnosis of pediatric infection-triggered autoimmune neuropsychiatric disorders associated with PANDAS according to the Diagnostic and Statistical Manual of Mental Disorders (DSM-R) [6]. Intravenous immunoglobulin (IVIg) has emerged as a useful adjunctive agent in the treatment of PANDAS [7].

\footnotetext{
Auctores Publishing - Volume1-10029 www.auctoresonline.org Page - 01

There has not been an analysis of the efficacy and outcome of patients in the literature with PANDAS treated with IVIg. The present analysis combines and contrasts published cases of PANDAS in the literature treated with IVIg therapy.

\section{Methods}

A search for publications related to the case reports of children with PANDAS who underwent treatment with IVIg therapy was carried out online in PubMed. This yielded seven articles [8-14] to which an eighth study [15] was added. Together the papers document 145 children who met established criteria [5] for the diagnosis of PANDAS and received treatment with IVIg therapy for neuropsychiatric symptoms. The cohort of 145 children described in Table 1 was comprised of one large observational study of 114 children all of whom were treated with IVIg [15], a single randomized control trial (RCT) of nine children comparing IVIg to placebo and plasma-exchange (PE) [9], three small case series totaling 21 children [8,11-14]; and a case abstract [10]. 
Treatment with IVIg was generally deemed necessary because of neuropsychiatric symptoms refractory to maximal conservative management that typically included prophylactic antibiotics and psychotropic medications.

\begin{tabular}{|c|c|c|c|c|c|c|}
\hline Author (Reference Number) & $\begin{array}{l}\text { Study } \\
\text { type }\end{array}$ & $\begin{array}{l}\text { Number } \\
\text { of cases }\end{array}$ & $\begin{array}{c}\text { Mean } \\
\text { AgetSD, years }\end{array}$ & Sex & $\begin{array}{l}\text { Mean Duration of } \\
\text { PANDAS } \pm S D \text {, years }\end{array}$ & Available Ig Data \\
\hline Allen eta [5] & cs & 1 & 13 & M & 0.08 & $\mathrm{NA}$ \\
\hline Bouboulisetal [14] & CS & 6 & $11 \pm 4.9$ & $M(50 \%)$ & $4.5 \pm 2.4$ & $\begin{array}{l}\text { All six patients had immune } \\
\text { deficiency, ralues } \mathbb{R}\end{array}$ \\
\hline Frankorich etal [12] & CS & 1 & 11 & M & 1.2 & $\mathbb{N A}$ \\
\hline Hachiyg et al [11] & cS & 1 & 7 & F & 0 & $N A$ \\
\hline Hershetal [10] & CR & 1 & 10 & M & 1 & $\lg 62 / \lg G 4$ deficiency \\
\hline Koracericetal [13] & cs & 12 & $10.3 \pm 2.9$ & $M(75 \%)$ & $2.4 \pm 2.3$ & $\mathrm{NA}$ \\
\hline Younger et al [15] & Observational sudy & 114 & $10.6 \pm 3.3$ & $M(64.9 \% 6)$ & $4.3 \pm 3.1$ & $\begin{array}{l}42.9 \% \text { patients had 1 or more lg } \\
\text { deficienciest }\end{array}$ \\
\hline Perlmutter etal [9] & $\mathrm{RCT}$ & 9 & $9.1 \pm 2.4$ & $\mathbb{N A}$ & $0.2 \pm 0.1$ & $\lg G, \operatorname{Ig} N$ NR; $N$ Oo Igh deficiencies \\
\hline
\end{tabular}

Table 1: Baseline Clinical Characteristics of 145 Cases (CR: case report; CS: case series; NA: not available; NR: not reported; RCT: randomized clinical trial. ${ }^{1}$ see text for details of Ig deficiencies.)

Clinical demographical characteristics at baseline such as age, sex, duration of PANDAS and IVIg treatment, dosage, regimens, and patient outcomes were abstracted in different studies and analyzed for mean values and associated percentages for continuous, categorical and discrete values.

\section{Results}

\section{Literature Review}

Allen and colleagues [8] reported successful treatment of symptomatic tics and OCD in a child with GABHS infection complicating Tourette's syndrome with IVIg in conjunction with penicillin prophylaxis. Perlmutter and colleagues [9] conducted a RCT comparing the outcome of OCD and tics among 29 children with PANDAS randomized to plasma exchange PE (10 children), IVIg (nine children) or saline solution placebo (10 children). The authors noted global score changes of $48 \%$ and $41 \%$ respectively at one month after treatment with 10 to 12 days of PE or 2 days of IVIg, compared to $87.5 \%$ and $77.7 \%$ in those respectively treated with PE or IVIg in open label at one year. Harsh and colleagues [10] reported a child with PANDAS in whom immunologic evaluation disclosed low $\mathrm{IgG} 2 / \mathrm{IgG} 4$ subclass levels, suboptimal response to pneumococcal vaccine and rapid decline of pneumococcal antibody titers with low levels of proinflammatory cytokines (tumor necrosis factor [TNF]-a, interleukin [IL]1-b, and 12p40) to liposaccharide without Toll-like receptor (TLR)4 polymorphisms (Asp299Gly and Thr3991le). Treatment with IVIg was associated with near complete resolution of Sino pulmonary infection and symptoms of PANDAS. Thirty-two additional children with PANDAS treated successfully with IVIg were reported in five cases series [11-14]. Bouboulis and Mast [14] noted the favorable impact of IVIg on neuropsychiatric manifestations of PANDAS and humoral deficiency in the patients however the nature and extent of the latter was not described. Younger and colleagues [15] extended the findings of Bouboulis and Mast [14] noting low serum immunoglobulin levels in any category in $52.56 \%$, and the favorable prognosis of children with baseline Ig deficiencies presumably in which IVIg acted as both replacement therapy and immune modulator.

\section{Statistical Analysis}

Table 1 and Table 2 summarize the clinical characteristics and outcome of the combined cohort of study patients. The male: female ratio was 1.9:1 with mean age 10.5 years, and mean duration of neuropsychiatric symptoms of 3.7 years before treatment with IVIg. Among the 145 children that comprised the study cohort, 120 $(83 \%)$ received IVIg therapy at doses between 1.0 and 2.0 grams per kilogram administered every 1 to 2 months for a mean duration of 15.3 months (range 0.03 - 61.79 months) for refractory neuropsychiatric symptoms associated with PANDAS;
$19(13 \%)$ children received a single course of therapy in the first month.

\begin{tabular}{|c|c|c|c|c|}
\hline $\begin{array}{l}\text { Author } \\
\text { (Reference Number) }\end{array}$ & $\begin{array}{l}\text { Dose per course, } \\
\mathrm{g} / \mathrm{kg}\end{array}$ & Dosing & $\begin{array}{l}\text { Total courses } \\
\text { (duration time) }\end{array}$ & Status at final assessment \\
\hline Allen et al [5] & 0.002 & & 1 course (over 2 days) & Symptoms improved \\
\hline Bouboulis et al [14] & 1.6 & Every 2 months & $\begin{array}{l}\geq 1 \text { course } \\
\text { (over } 2 \cdot 24 \text { months) }\end{array}$ & 4 had improved symptoms and 2 achieved remission \\
\hline Frankovich et al [12] & 2 & & 1 course & Symptoms improved \\
\hline Hachiya et al [11] & $\mathrm{NA}$ & & $\mathrm{NA}$ & Symptoms improved gradually \\
\hline Hersh et al [10] & 0.6 & Every 3 weeks & $\mathrm{NA}$ & Achieved remission \\
\hline Kovacericetal [13] & 1.5 & & $\begin{array}{c}6 \text { took } 1 \text { course and } 6 \text { took } 2 \\
\text { separate courses }\end{array}$ & 2 had improved symptoms and 10 achieved remission \\
\hline Younger et al [15] & $1.0 \cdot 2.0$ & Every 1 to 2 months & $\begin{array}{l}\text { Average } 7.5 \text { courses } \\
\text { (over } 15.7 \text { months) }\end{array}$ & $\begin{array}{l}78(64.4 \%) \text { had improved symptoms and } 22(19.3 \%) \\
\text { achieved remission at } 12 \text {-month follow-up }\end{array}$ \\
\hline Perlmutter et al [9] & 2.0 & & $\begin{array}{c}1 \text { course } \\
\text { (over } 2 \text { days) }\end{array}$ & $\begin{array}{l}\text { Global change scores* were improved by } 53 \% \\
\text { at 12-month follow-up }\end{array}$ \\
\hline \multicolumn{5}{|c|}{$\begin{array}{l}\text { * Clinical Global Impression (CGI) change scale assesses the patient's improvement or worsening from baseline which rates as } 1 \text { =very much improved, } \\
2=\text { much improved, } 3=\text { minimally improved, } 4=\text { no change, } 5=\text { minimally worse, } 6=\text { much worse, and } 7 \text { =very much worse. At } 1 \text { month, the mean of clinical } \\
\text { global impression change score is } 2.4(\mathrm{SD}=1.1) \text {, at } 1 \text { year the mean of score is } 2.3(\mathrm{SD}=1.1) \mathrm{NA} \text {, not avalable. }\end{array}$} \\
\hline
\end{tabular}

Table 2: Treatment and Outcome.

Altogether, $87(60 \%)$ were clinically improved, 35 (24\%) achieved remission, and $14(10 \%)$ were unchanged or worse at final assessment in the one large observational study [15]. Baseline Ig levels were documented in only two studies showing low IgG subclass 2 and 4 levels [10], and low levels of serum IgG subclasses, total IgG, IgM and IgA respectively in $26.47 \%, 25.51 \%, 16.28 \%$, and $10.48 \%$ of cases [15]. Among 114 patients [15], 49 (35\%) had low baseline Ig levels. Of 22 patients $(19.3 \%)$ who achieved remission, all $22(100 \%)$ had low baseline IgG (20 patients) or IgG subclass levels ( 2 patients), alone (8 patients) or together (6 patients) or in association with reduced IgA or IgM levels (8 patients), indicative of humoral deficiency prior to IVIg treatment [15]. One reported patient who achieved remission [10] had combined $\operatorname{IgG} 2 / 4$ subclass deficiency.

Low levels of $\operatorname{IgA}(\mathrm{p}<0.006), \operatorname{IgG}(\mathrm{p}<0.0001)$ and $\operatorname{IgG}$ subclasses $(\mathrm{p}<$ 0.0003 ) were associated with $100 \%$ improvement at 12 months, while age, sex, duration of disease, and baseline IgM levels were not associated with IVIg efficacy [15].

Mild adverse effects of treatment so noted in $16 \%$ of patients in the one large observational study [15] included exacerbation of migraine headache or flu symptoms at the beginning of therapy that did not preclude ongoing treatment and was generally managed with slowing the rate of infusion, vigorous hydration, or a change in IVIg product.

\section{Discussion}

Intravenous $\mathrm{Ig}$ provides replacement $\mathrm{Ig}$ in immunodeficiency and immunomodulation in the treatment of inflammatory autoimmune pediatric diseases [16]. From immunodeficiency to autoimmunity, the dynamic immunologic basis of PANDAS highlights the broad potential of high-dose IVIg therapy. One small early published RCT [9] and clinically similar case reports [8;10-14] demonstrated improvement or remission similar to a recent large observational study [15] that showed benefit of IVIg for up to $84 \%$ of children with PANDAS concomitant with, or following treatment at one-year final assessment [15].

Our study had several limitations mainly associated with lack of uniformity within and among the published cases of PANDAS that precluded statistically meaningful comparisons. First, the dose, duration of treatment and timing of IVIg therapy was not uniform with some patients treated for one month and others repeatedly. Second, there was lack of uniform assessment of response to IVIg with employment of different methods of scoring. A change in a global assessment score summing OCD symptoms, tic severity, global measures of symptoms severity and psychosocial functioning were used in the RCT [9], while quartile scales of percentage improvement were employed in the observational study [15] in assessing response to treatment at one month and one-year follow-up. None of the patients described in case reports were objectively scored at onset or after one month or 12 months of treatment. 
Third, it was not possible to ascertain the beneficial effects of concomitantly prescribed medications such as chronic or prophylactic antibiotics or psychotropic agents in the response to IVIg. Fourth, there were no data in regard to patient's clinical status between the long intervals of assessment. Neither was it possible to ascertain whether unrelated bouts of exacerbation and improvement may have influenced the response attributed to IVIg. Fifth, with a mean treatment period of 15.7 months (SD $=13.8$ months) in the observational study [15], nearly half of patients were assessed while receiving IVIg leading to a possible excess of positive cases compared to those treated for a shorter time. Lastly, baseline Ig status was described in only two studies [10,15], including one that selected patients for treatment with IVIg because of immune deficiency [14] but did not provide further detailed information relevant to it.

The nosology and classification of autoimmune neuropsychiatric disorders is rapidly evolving [17], and the recognition that some affected children have infectious and immunologic triggers emphasizes the importance of new avenues of treatment. Intravenous Ig is a safe and useful adjunctive therapy in the treatment of refractory neuropsychiatric symptoms due to PANDAS and its variants. Children with PANDAS, often with baseline humoral immune deficiency derived a favorable response to IVIg in PANDAS at 12 months follow up consistent with its role in Ig replacement and immune modulation. While its use has not been substantiated in a large RCT, our findings support the use of IVIg early in the course of the disease and continued until significant improvement or remission is achieved often without serious side-effects. There is an urgent need for standardized guidelines to address the selection of patients and the most appropriate dosing regimens in those with refractory neuropsychiatric symptoms due to PANDAS.

\section{References}

1. Swedo SE, Rapoport JL, Leonard H, Lenane M, Cheslow D. Obsessive-compulsive disorder in children and adolescents: clinical phenomenology of 70 consecutive cases. Arch Gen Psychiatry. 1989;46(4):335-41.

2. Leonard HL, Lenane MC, Swedo SE, Rettew DC, Gershon ES, Rapoport JL. Tics and Tourette's disorder: a 2 to 7-year followup of 54 obsessive-compulsive children. Am J Psychiatry. 1992;149(9):1244-51.

3. Rettew DC, Swedo SE, Leonard HL, Lenane MC, Rapoport JL. Obsessions and compulsions across time in 79 children and adolescents with obsessive compulsive disorder. J Am Acad Child Adolesc Psychiatry. 1992;31(6):1050-6.

4. Swedo SE. Sydenham's chorea: a model for childhood autoimmune neuropsychiatric disorders. JAMA 1994; 272(22):1788-91.

5. Swedo SE, Leonard HL, Garvey M, Mittleman B, Allen AJ, Perlmutter S, et al. Pediatric autoimmune neuropsychiatric disorders associated with streptococcal infections: clinical description of the first 50 cases. Am J Psychiatry. 1998;155(2):264-71.
6. American Psychiatric Association. Diagnostic and statistical manual of mental disorders: Dsm-3-R. 3rd ed. American Psychiatric Association, Washington, DC: American Psychiatric Association, 1987.

7. Vitaliti G, Tabatabaie O, Matin N, Ledda C, Pavone P, Lubrano R, et al. The usefulness of immunotherapy in pediatric neurodegenerative disorders: A systematic review of literature data. Hum Vaccin Immunother. 2015;11(12):2749-63. doi: 10.1080/21645515.2015 .1061161 .

8. Allen AJ, Leonard HL, Swedo SE. Case study: A new infectiontriggered autoimmune subtype of pediatric OCD and Tourette's syndrome. J Am Acad Child Adolesc Psychiatry. 1995;34(3):307-11.

9. Perlmutter SJ, Leitman SF, Garvey MA, Hamburger S, Feldman E, Leonard HL, et al. Therapeutic plasma exchange and intravenous immunoglobulin for obsessive-compulsive disorder and tic disorders in childhood. Lancet. 1999;354(9185):1153-8.

10. Hersh ALB, Geng A, Cushing-Ruby H, Jyonouchi H. Resolution of PANDAS like symptoms by IVIg in a patient with specific antibody deficiency against polysaccharide antigens (Abstract). J Allergy Clin Immunol 2006; 117(2):S519.

11. Hachiya Y, Miyata R, Tanuma N, Hongou K, Tanaka K, Shimoda K, et al. Autoimmune neurological disorders associated with group-A beta-hemolytic streptococcal infection. Brain Dev. 2013;35(7):670-4. doi: 10.1016/j.braindev.2012.10.003.

12. Frankovich J, Thienemann M, Rana S, Chang K. Five youth with pediatric acute-onset neuropsychiatric syndrome of differing etiologies. J Child Adolesc Psychopharmacol. 2015;25(1):31-7. doi: 10.1089/cap.2014.0056.

13. Kovacevic M, Grant P, Swedo SE. Use of intravenous immunoglobulin in the treatment of twelve youths with pediatric autoimmune neuropsychiatric disorders associated with streptococcal infections. J Child Adolesc Psychopharmacol. 2015;25(1):65-9. doi: 10.1089/cap.2014.0067.

14. Bouboulis DA, Mast PA. Infection-induced autoimmune encephalopathy: Treatment with intravenous immune globulin therapy. A report of six patients. Int J Neurology Res. 2016; 2:256258.

15. Younger DS, Mast PA, Bouboulis DA. Baseline Immunoglobulin Levels Predict Achievement of Remission at One Year Following IVIg Therapy. J Neurol Neurosurgy. 2016; 3(2):122.

16. Wong $\mathrm{PH}$, White KM. Impact of immunoglobulin therapy in pediatric disease: a review of immune mechanisms. Clin Rev Allergy Immunol. 2015.

17. Pavone P, Parano E, Rizzo R, Trifiletti RR. Autoimmune neuropsychiatric disorders with streptococcal infection: Sydenham chorea, PANDAS, and PANDAS variants. J Child Neurol. 2006;21(9):727-36. 